\title{
ABSENCE OF MIDDLE TRUNK OF BRACHIAL PLEXUS: AN UNCOMMON VARIATION
}

Manmohan Patel ${ }^{1}$, Abhijeet Yadav², Monika Srivastava ${ }^{3}$, Asha Dixit $^{4}$

HOW TO CITE THIS ARTICLE:

Manmohan Patel, Abhijeet Yadav, Monika Srivastava, Asha Dixit. "Absence of middle trunk of brachial plexus: an uncommon variation". Journal of Evolution of Medical and Dental Sciences 2013; Vol2, Issue 39, September 30; Page: 7468-7471.

ABSTRACT: During routine dissection of a middle aged male cadaver, it was found that the middle trunk of brachial plexus was missing on left side. The Upper trunk was formed from union of C5, C6 and $\mathrm{C} 7$ while the lower trunk was normal having union of C8 and T1. Rest of the plexus below cord and on right side was normal. Erb's point was present there having fibres of C5, 6\&7. Knowledge of Variation in brachial plexus is very important for orthopaedic surgeons, neurosurgeon and anesthesiologists.

KEY WORDS: Brachial plexus, trunk, division, cord, variation.

INTRODUCTION: The brachial plexus is formed by the union of the ventral rami of the inferior four cervical (C5-C8) and first thoracic (T1) nerves. The C5 nerve usually receives a small contribution from the fourth-cervical nerve and the T1 nerve normally receives one from the second thoracic nerve. The brachial plexus is the main source of innervations to the upper limbs. Any injury at trunk level can lead to significant disability. The ventral rami of C5 and C6 cervical nerves unite to form the superior trunk. That of $\mathrm{C} 7$ nerve runs alone as the middle trunk and those of $\mathrm{C} 8$ and $\mathrm{T} 1$ nerves unite to form the inferior trunk; each of the trunks then bifurcates into anterior and posterior divisions as they pass beneath the clavicle. The anterior divisions of the superior and middle trunk form the lateral cord. The anterior division of the inferior trunk continues as the medial cord.

The posterior divisions of all three trunks unite to form the posterior cord. From the cords arise the terminal branches of the brachial plexus.i Variations in the trunk formation in brachial plexus are relatively rare as compared to the cords and terminal branches formations. The presence of anatomic variations is often used to explain symptoms that might not otherwise be obvious.

CASE REPORT: During routine dissection of the left side of neck in posterior triangle for routine teaching purposes, a rare variation of the brachial plexus organization was found in a middle aged male cadaver. Complete dissection of the neck was done and the roots were followed up to the intervertebral foramina by removing scalenus anterior muscle. The axillary region, arm, and hand were dissected earlier showing normal anatomical pattern of nerves. Dissection revealed the absence of the middle trunk on the left side. The ventral rami of C5, C6 and C7 joined to form the superior trunk and the formations of the lower trunks were normal by union of C8 and T1. The upper trunk was giving suprascapular nerve and nerve to subclavius. Both upper and lower trunks divide into ventral and dorsal divisions. Dorsal divisions of upper and lower trunks united to form posterior cord of brachial plexus while ventral division of upper and lower trunks continued as lateral and medial cord respectively (Fig. -1). The cadaver was dissected on right side also and the findings were normal. Other structures in the region of posterior triangle of neck were normal. 


\section{CASE REPORT}

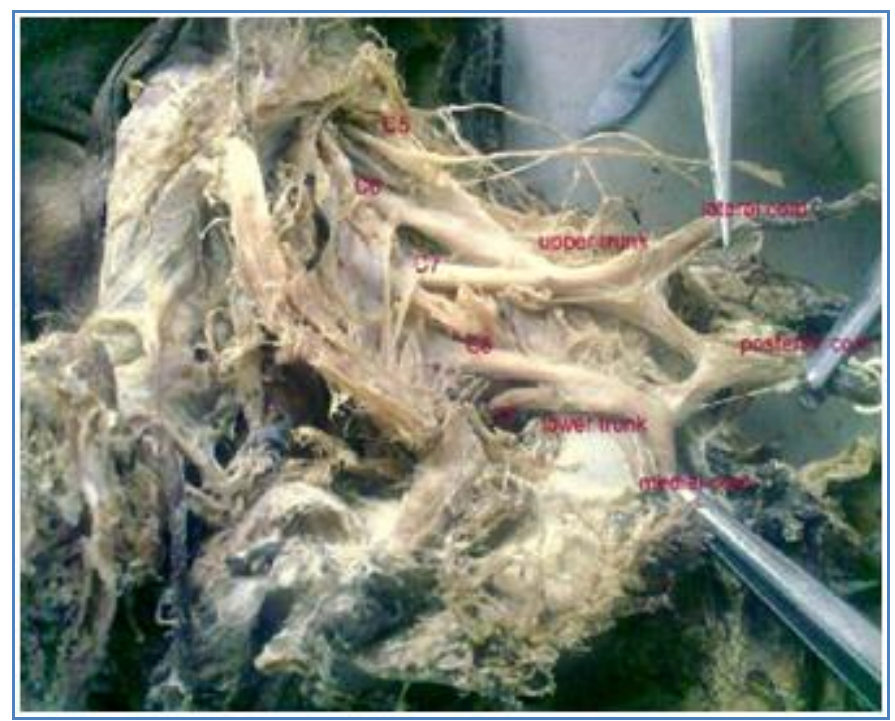

Fig. 1: Showing absence of middle trunk of brachial plexus.

DISCUSSION: Knowledge of variations in anatomy is important to clinicians, especially in radiological diagnoses and surgical procedures. Variations in the contributions to the plexus may be correlated with the position of the limb bud in embryo and the nerves first grow into. Many variations are similar to the normal forms of the brachial plexus found in different primates.

Variations in the formation of the trunks are very rare, trunk variations have been noted in the literature. In particular, the absence of the inferior trunk characterized by the non-union of C8 and T1 nerve roots has been reported. The absence of the middle trunk has also been observed. The ventral rami of the $\mathrm{C} 5, \mathrm{C} 6$, and $\mathrm{C} 7$ nerve roots have been found to form the superior trunk at the expense of an absent middle trunk [4-6]. Formation of upper trunk of brachial plexus by C5, C6 and C7 roots can also interpreted as anatomical fusion of upper and middle trunks. One such abnormal upper trunk has been reported by Nayak et al. (2005) [7]. The C7, C8 and T1 nerve roots have been shown to form the inferior trunk with the absence of the middle trunk [4]. A case of bilateral fusion of upper and middle trunks of brachial plexus was also reported by Matejcik V et al. [8] A study by Uysal et al. revealed that the absence of the superior trunk was less common than the absence of the inferior trunk. The superior trunk was not formed in two plexuses (1\%) while the inferior trunk was not formed in eighteen plexuses (9\%) [3]. Shetty et al. studied 44 dissected specimens specifically for variations in the formation of the trunks of the brachial plexus. $11.3 \%$ showed variations in the formation of the trunks. All the variations were unilateral. In $2.27 \%$ the middle trunk was formed by union of C7 and C8 roots and lower trunk was formed by T1 root. Upper and middle trunks were fused with each other in $2.27 \%$. In $6.81 \%$ the C5 root pierced scalenus anterior before joining $\mathrm{C} 6$ to form the upper trunk.[9] Variations in trunk of brachial plexus which can be find out by ultrasound examinations, so it is better to look for variations before planning the surgery in this area [10]. Gerevin et al. has stated that the brachial plexus MRI provides a topographic localization of the tumour showing the nerve dislocations or infiltration by the neoplasm. In traumatic patients they suggest that the brachial plexus MRI could be useful to detect the degree of axonal damage when the nerve lesion is in continuity. A standardized brachial plexus MRI protocol has an invaluable 


\section{CASE REPORT}

diagnostic value for the surgeons and neurologists. It is only limited by its duration (at least $45 \mathrm{~min}$ ). [11]

In context of upper trunk brachial plexus injury (Erb's paralysis) this case will not manifest characteristic (waiter' tip position) or typical (porter's tip) deformity. Hence the spectrum of clinical manifestations produced by upper trunk injury in the present case will be entirely different from the classic Erb's palsy and may mislead the clinicians. As the nerves were normal in distal part of brachial plexus it is uncertain whether it will cause any clinical problem. The knowledge of variations in the formation of brachial plexus is very useful for neurosurgeons for surgical treatment of tumours of nerve sheaths. Orthopaedic procedures of the cervical spine also need a thorough knowledge of the normal and abnormal formation of brachial plexus Awareness of variations in neurovascular anatomy allows physicians to derive more specific differential diagnoses.

CONCLUSION: This case of absence of middle trunk variation is a rare anomaly. Nerve injuries in such cases will not be presented with characteristic features leading to confusion in diagnosis. Though it is a rare variation neurosurgeon, orthopaedic surgeons and radiologists should always aware of them.

\section{REFERENCES:}

1. Standring S, editor-in-chief. Gray's Anatomy 39th Ed., Edinburgh, New York, Churchill \& Livingstone, 2005; 1600.

2. Miller RA, Detwiller SR. Comparative studies upon the origin and development of the brachial plexus. Anat Rec 1936; 65: 273-92.

3. Uysal II, Seker M, Karabulut AK, Buyukmumcu M, Ziylan T. Brachial plexus variations in human fetuses. Neurosurgery. 2003; 53: 676-684.

4. Matejcik V. Aberrant formation and clinical picture of brachial plexus from the point of view of a neurosurgeon. Bratisl. Lek. Listy. 2003; 104: 291-299.

5. Prakash, Prabhu LV, Kumar J, Singh G. Brachial plexus with two trunks and double axillary veins: applied importance and clinical implications. Firat Tip Dergisi. 2006; 11: 210-212.

6. Nayak S, Somayaji N, Vollala VR, Raghunathan D, Rodrigues V, Samuel VP, Alathady Malloor P. A rare variation in the formation of the upper trunk of the brachial plexus - a case report. Neuroanatomy. 2005; 4: 37-38.

7. Nayak, S.; Somayaji, N; Vollala, V. R.; Raghunathan, D; Rodrigues, V; Samuel, V. P \& Alathady Malloor, P. A rare variation in the formation of the upper trunk of the brachial plexus - a case report. Neuroanatomy, 4(1):37-8, 2005.

8. Matejcik V. Anatomical variations in the brachial plexus trunks and nerve roots. Rozhl Chir 2003; 82: 450-459.

9. Shetty, S. D.; Nayak, B. S.; Madhav, V.; Braganza, C. S. \& Somayaji, S. N. A study on the variations in the formation of the trunks of brachial plexus. Int. J. Morphol., 29(2):555-558, 2011.

10. Royse, C. E.; Sha, S.; Soeding, P. F. \& Royse, A. G. Anatomical study of the brachial plexus using surface ultrasound. Anaesth. Intensive Care, 34(2):203-10, 2006. 
11. Simonetta Gerevini, Carlo Mandelli, Marcello Cadioli and Giuseppe Scotti ' Diagnostic value and surgical implications of the magnetic resonance imaging in the management of adult patients with brachial plexus pathologies' JCDR/2011/1800Volume 30, Number 2, 91-101.

\section{AUTHORS:}

1. Manmohan Patel

2. Abhijeet Yadav

3. Monika Srivastava

4. Asha Dixit

\section{PARTICULARS OF CONTRIBUTORS:}

1. Assistant Professor, Department of Anatomy, All India Institute of Medical Sciences, Bhopal.

2. Assistant Professor, Department of Anatomy, Bundelkhand Medical College, Sagar.

3. Post Graduate Student, Department of Anatomy, Gandhi Medical College, Bhopal.
4. Professor and Head, Department of Anatomy, Gandhi Medical College, Bhopal.

\section{NAME ADDRESS EMAIL ID OF THE CORRESPONDING AUTHOR:}

Dr. Abhijeet Yadav,

Flat No. 8, Block 9,

BMC Campus, Sagar, M.P.

Email-dr.abhijeetrocks@gmail.com

Date of Submission: 16/09/2013.

Date of Peer Review: 17/09/2013.

Date of Acceptance: 23/09/2013.

Date of Publishing: 25/09/2013 